\title{
Epidemiological Risk Factors Influencing the Formation of Renal Calculi, their Chemical Composition and Association with Urinary Tract Infections
}

\author{
P. Sri Lakshmi ${ }^{1}$, Kalyan Kumar Kakarla ${ }^{1}$, Pendru Raghunath ${ }^{2}$, Y. V. Ramakrishna Reddy ${ }^{1}$ * \\ ${ }^{1}$ Department of Biochemistry, Mamata Medical College, Khammam, Telangana 507002, India \\ ${ }^{2}$ Associate Professor, Department of Microbiology, Dr. VRK Women's Medical College, Hyderabad, Telangana 500075, India
}

\begin{abstract}
DOI: $\underline{10.36348 / \mathrm{sijb} .2020 . \mathrm{v} 03 \mathrm{i} 12.005}$
| Received: 13.12.2020 | Accepted: 24.12.2020 | Published: 30.12 .2020

*Corresponding author: Y. V. Ramakrishna Reddy
\end{abstract}

\section{Abstract}

This study was conducted to assess the influence of epidemiological risk factors in the formation of renal calculi, their compositionand association with urinary tract infections (UTI) among the ethnic population of Khammam district, Telangana state. This study included 56 subjects attending the urology department, Mamata General Hospital, Khammam. Out of 56 patients with renal calculi, 50 are male, 46 from rural areas, 22 were farmers and 26 were manual labor. Twenty six belonged to socioeconomically lower middle class, 38 were non-vegetarians and 47 were consuming bore/tank water. Results of this study suggest a significant association between all the epidemiological risk factors viz., gender, residence, occupation, socio economic status, diet, and source of water and formation of renal calculi. Structural analysis of stones demonstrated that $78.6 \%$ of stones were mixed. Overall, calcium oxalate as pureor mixed with otherchemicals was the main component of stones matrix, seen in $38(67.9 \%)$ patients. In this study, struvite is present in $21.4 \%$ of the stones. Thirty $(53.6 \%)$ of 56 urine specimens were culture positive and $26(46.4 \%)$ were sterile. All the positive urine cultures yielded a single organism and 26of 30 isolates were positive for urease enzyme. Klebsiella was the most common organism and was isolated from $16(28.6 \%)$ urine samples. Results suggest that there is a significant association between UTI and renal calculi formation.

Keywords Epidemiological risk factors. Renal calculi. Chemical composition. Urinary tract infection.

Copyright () 2020 The Author(s): This is an open-access article distributed under the terms of the Creative Commons Attribution 4.0 International License (CC BY-NC 4.0) which permits unrestricted use, distribution, and reproduction in any medium for non-commercial use provided the original author and source are credited.

\section{INTRODUCTION}

Renal calculus formation is seen as a common worldwide clinical problem; basically the formation of calculi occur in kidney (nephrolithiasis), ureter (ureterolithiasis) and urinary bladder (cystolithiasis) by the succeedingphysico-chemicalevents of super saturation, nucleation, aggregation, andfinally preservation [1]. The crystal is formed by the components like calcium oxalate, calcium phosphate, calcium carbonate, magnesium-ammonium phosphate, uric acid, and cysteine [2]. Calcium stones are predominant renal stonescomprising about $80 \%$ of all urinary calculi [3]. Struviteor Magnesium Ammonium Phosphate stones occur to the extent of $10-15 \%$ and havealso been referred to as infection stones and triple phosphate stones. Struvite stones occur among patients with chronic urinary tract infections that produce urease $[3,4]$. Women's are likely to develop this type of stone than the male.Uric Acid Stonesaccount for approximatelyfor $3-10 \%$ of all stone types [3, 5]. Diets high in purinesespecially those containing animal protein diet such as meatand fish, results in hyperuricosuria, low urine volume, andlow urinary $\mathrm{pH}$ $(\mathrm{pH}<5.05)$ exacerbates uric acid stone formation $[4,6$, 7].

Renal calculi are perceived as acute disorder but the growing stage of urolithiasis is a systemic disease that can lead to end stage renal disorder.Formation of kidney stones is common worldwide; often debilitating that has different etiology, pathophysiology and affecting all geographical regions throughout the globe. Annual approximate prevalence is $3-5 \%$ and approximate life time prevalence is $15-25 \%$. Nephrolithiasis tend to be recurrent in most of the renal calculi patients. Recurrence rates of renal stone are approximately $10 \%$ year, $50 \%$ over a period of $5-10$ years and $75 \%$ over 20 years period [8].The incidence rate of renal calculi varies with geographical region of an individual country. Incidence is $13 \%$ in North America, 5-9\% in Europe and $1-5 \%$ in Asia [9, 10].Geographically, high frequency was foundin United States, Middle East, Mediterranean countries, 
Scandinavian countries, the British Isles, and Central Europe. In Asia, a stone-forming belt has been reported to extend across India, Indonesia, Iran, Myanmar, Pakistan, the Philippines, Saudi Arabia, Sudan, Thailand and the United Arab Emirates [11]. In India, the incidence of kidney stones is $15 \%$ (approximately 5 to 7 million) [12]. Approximate 2 million people in India is affected with nephrolithiasis every year and some parts of country has name denoted as a stone belt that is, Gujarat, Maharashtra, Punjab, Rajasthan, Delhi, Haryana and part of states on North East side [13]. Renal calculi are also found in south India due to high intake of tamarind in regular diet [14].

In most countries, males are predisposed to renal calculi,with male to female ratio ranging from 1.3 to 5 [15-17]. Overall, the incidence of urinary tract stones increasedwith age, which peaked in the age group of 30-60 years and decreased afterwards [18]. Patientswith urine volume is $<1 \mathrm{~L} /$ day are prone to develop renal stones [19] and patients with renal stones are instructed to maintain a high fluid intake in order to produce at least $2.5 \mathrm{~L}$ of urine in 24 hours $[20,21]$. This multi-factorial disease occurs as a result of the combined influence of epidemiological, biochemical, genetic, and metabolic risk factors [22].

Bacteria and renal calculi are clinically associated because they often occur in the same patients and patients with renal calculi often have positive urine and/or stone cultures. The relationship between renal calculi and urinary tract infections (UTI) is complex and difficult to analyze bothon a pathophysiological and clinical point of view. Bacteria have long been recognized to contribute to struvite urinary stones; however, the role of bacteria in the development of the more common calcium oxalate and calcium phosphate stones has not been extensively investigated. Several recent studies also indicate a possible association between urinary stones and bacteria, including the high rate of UTI in urinary stone patients and multiple case series of culture-positive urinary stones, including stones composed of calcium oxalate or calcium phosphate [23]. Calcium-based stones might also become secondarilyinfected with urease-splitting organismsand result in secondary struvite stone formation. These stones may contain a mixture of struvite and other materials [24, 25]. Previous reports suggest increased crystal clumping in the presence of bacteria, bacteria-induced lower urine citrate levels and increased $\mathrm{CaOx}$ deposits and stone matrix protein expression when bacteria are present as opposed to $\mathrm{CaOx}$ deposits alone [23].

Prevention of renal calculi recurrences remains to be a serious problem in human health [26]. Prevention of stone recurrencerequires better understanding of risk factors and the mechanismsinvolved in stone formation. Hence, this study is taken up to assess the influence of epidemiological risk factors like age, gender, occupation, socioeconomic status, source of water and dietary habits of an individual'son kidney stone formation among the ethnic population of Khammam district, Telangana. This study also aimed at determining the association between formation of renal calculi and urinary tract infections.

\section{PATIENTS AND METHODS}

This study included 56 patients, out of whom 50 were male and 6 female patients.Patients who underwent surgery for vesiclecalculus at Mamata General and Super Specialty Hospital, Khammam, from March 2018 to March 2019 were included in this study. Patients with calculi $\geq 2.5 \mathrm{~cm}$ were included to compare trans-urethral cysto-lithotripsy and open cystolithotomy. Patients having bladder stones in augmented bladder were excluded from the study.Patient's written consent and study methodology approval by the institutional ethical committee was obtained.

Patients were subjected to the preformatted study methodology including detail history taking, clinical examination, routine laboratory investigations, relevant special investigations (Ultrasound abdomen/ X-ray KUB/ IVP/ CT-KUB). Samples were taken from the removed stones at the time of operation and samples of urine were obtained through simultaneous bladder catheterization. After washing the stone several times with normal saline and softening the stone fragments, a homogenous dilution of the softened stone was prepared in saline. Samples from these prepared specimens were sent for chemical analysis [27]. Urine specimens were inoculated onto appropriate culture media for identification of urease-producing bacteria as well as common gram positive and gram negative bacteria. The results of urine cultures were considered positive if growth of $\geq 100.000 \mathrm{CFU} / \mathrm{mL}$ was observed after $24 \mathrm{~h}$. The negative cultures were re-examined after an additional $24 \mathrm{~h}$ for confirmation.Bacterial isolates were subjected to a series of biochemical tests for identification. Results were analyzed by using the SPSS-20.0 version (Non-Parametric chi-square analysis). The results were considered significant at $\mathrm{p}<0.05$ level.

\section{RESULTS}

The present study was conducted to assess the influence of epidemiological risk factors in the formation of renal calculi.Out of 56 patients with renal calculi, 50 are male, 46 from rural areas, 22 were farmers and 26 were manual labor (Table-1). Twenty six belonged to socioeconomically lower middle class, 38 were non-vegetarians and 47 were consuming bore/tank water (Table-1).

Structural analysis of stones demonstrated that $44(78.6 \%)$ of 56 were mixed. We have found that 19 $(34 \%)$ of 56 stones were formed with the combination of calcium oxalate, calcium phosphate stones, and 7 
(12.5\%) of 56 stones were composed of calcium oxalate \&magnesium ammonium phosphate (Struvite) (Table2). Overall, calcium oxalate as pureor mixed with other chemicals was the main component of stones matrix, seen in 38 patients $(67.9 \%)$ (Table-2).

Thirty $(53.6 \%)$ of 56 urine specimens were culture positive and $26(46.4 \%)$ were sterile (Table 3 ). All the positive urine cultures yielded a single organism and 26 (Klebsiella species-16 and Proteus species-10) of 30 isolates were positive for urease enzyme. Klebsiella was the most common organism and was isolated from $16(28.6 \%)$ urine samples. Proteus was isolated from $10(17.9 \%)$ urine samples, followed by Escherichia coli (5.4\%) and Staphylococcus aureus $(1.8 \%)$.

The chi-square values for all the epidemiological risk factors viz., gender, residence, occupation, socio economic status, diet, and source of waterarefound to be significant (Table-4). The chisquare values for urine culture and stone chemical composition were also significant (Table-4).

Table-1: Influence of epidemiological risk factors for stone formation

\begin{tabular}{|l|l|l|l|}
\hline Parameters & Observed & Expected & Residual \\
\hline Gender & & & \\
\hline Male & 50 & 28.0 & 22.0 \\
\hline Female & 6 & 28.0 & -22.0 \\
\hline Residence & & & \\
\hline Rural & 46 & 28.0 & 18.0 \\
\hline Urban & 10 & 28.0 & -18.0 \\
\hline Occupation & & & \\
\hline Manual Labor & 26 & 14.0 & 12.0 \\
\hline Farmer & 22 & 14.0 & 8.0 \\
\hline Business & 5 & 14.0 & -8.0 \\
\hline Student & 2 & 14.0 & -12.0 \\
\hline Socio economic status & & & \\
\hline Lower Middle & 26 & 11.2 & 14.8 \\
\hline Upper lower & 13 & 11.2 & 1.8 \\
\hline Upper middle & 11 & 11.2 & -0.2 \\
\hline Upper & 3 & 11.2 & -8.2 \\
\hline Lower & 3 & 11.2 & -8.2 \\
\hline Diet & & & \\
\hline Non-vegetarian & 38 & 28.0 & 10.0 \\
\hline Vegetarian & 18 & 28.0 & -10.0 \\
\hline Source of water & & & \\
\hline Bore/tank & 47 & 28.0 & 19.0 \\
\hline Mineral water & 9 & 28.0 & -19.0 \\
\hline
\end{tabular}

Table-2: Structural analysis of renal calcul

\begin{tabular}{|c|c|c|c|}
\hline Parameters & Observed & Expected & Residual \\
\hline \multicolumn{4}{|l|}{ Stone Analysis } \\
\hline Calcium oxalate mixed with calcium phosphate & 19 & 4.3 & 14.7 \\
\hline Calcium oxalate mixed with magnesium ammonium phosphate (Struvite) & 7 & 4.3 & 2.7 \\
\hline Calcium oxalate (Pure) & 5 & 4.3 & 0.7 \\
\hline Uric acid (pure) & 4 & 4.3 & -0.3 \\
\hline Uric acid mixed with calcium phosphate & 4 & 4.3 & -0.3 \\
\hline Calcium phosphate mixed with magnesium ammonium phosphate (Struvite) & 4 & 4.3 & -0.3 \\
\hline Calcium phosphate (pure) & 3 & 4.3 & -1.3 \\
\hline Uric acid mixed with magnesium phosphate & 2 & 4.3 & -2.3 \\
\hline Calcium oxalate mixed with ammonium urate & 2 & 4.3 & -2.3 \\
\hline Uric acid mixed with calcium oxalate & 2 & 4.3 & -2.3 \\
\hline Calcium oxalate mixed with calcium phosphate, and ammonium urate & 2 & 4.3 & -2.3 \\
\hline Calcium phosphate mixed with ammonium urate & 1 & 4.3 & -3.3 \\
\hline $\begin{array}{l}\text { Calcium oxalate mixed with Calcium phosphate, and magnesium ammonium } \\
\text { phosphate (Struvite) }\end{array}$ & 1 & 4.3 & -3.3 \\
\hline
\end{tabular}


Table-3: List of urinary bacterial isolates from patients with renal calculi

\begin{tabular}{|l|l|l|l|}
\hline Bacteria & Observed & Expected & Residual \\
\hline Klebsiella species & 16 & 11.2 & 4.8 \\
\hline Proteusspecies & 10 & 11.2 & -1.2 \\
\hline Escherichia coli & 3 & 11.2 & -8.2 \\
\hline Staphylococcus aureus & 1 & 11.2 & -10.2 \\
\hline Sterile (No growth) & 26 & 11.2 & 14.8 \\
\hline
\end{tabular}

Table-4: Chi-Square analysis

\begin{tabular}{|l|l|l|l|}
\hline Parameter & Chi-Square & Difference & Asymp.Sig \\
\hline Gender & 37.7 & 1 & 0.00 \\
\hline Residence & 23.14 & 1 & 0.00 \\
\hline Occupation & 29.14 & 3 & 0.00 \\
\hline Socio Economic Status & 31.85 & 4 & 0.00 \\
\hline Diet & 7.14 & 1 & 0.00 \\
\hline Source of water & 25.78 & 1 & 0.00 \\
\hline Urine Culture & 37.03 & 4 & 0.00 \\
\hline Stone Chemical Analysis & 62.39 & 12 & 0.00 \\
\hline
\end{tabular}

\section{DISCUSSION}

The male $(n=50)$ preponderance of renal stonesin our study was similar to that of other studies [22, 28-30]. Reports from most of the countries suggest that males are predisposed to develop renal calculi, with male to female ratio ranging from 1.3 to 5 [15-17]. This may be attributed to the different dietary habits and hormonal effects [31].Welshman and McGeown demonstrated increasedcitrate concentrations in the urine of women [32]. It has been postulated that this mayaid in protecting females from development of calcium stones since citrateinhibits nucleation of calcium oxalate crystals [33]. Testosterone might promote the formation of urinary stones, while estrogen appears to inhibit by regulating the synthesis of 1,25dihydroxy-vitamin D [18].Additionally, anatomical differences in urinary tract between males and females; in male the urethra is longer than in female which may cause accumulation and stagnation of urine in the bladder for longer times.

In our study, $46(82.1 \%)$ of 56 patients were residing in rural areas. This result is in line with Stamatiou and colleagues [34] report, in their study they have shown that a significant percentage of the population with urolithiasis in rural areas (15.2\%). Wang et al., [35] did not observe any significant differences in the prevalence of kidney stone formation between urban and rural populations. Sas et al., [36] also reported that there were no differences in the incidence of renal calculi in children from urban and rural areas, but these results cannot be directly compared to the adult population. However, Prakash et al., [37] reported that the incidence of kidney stones was higher in the urban population.

The role of occupation or education level in the formation of renal calculi is still controversial [38]. Some research reports suggested that people with sedentary jobs (usually with high education level) are more prone to develop kidney stones; however, other reports suggested a positive relationship between kidney stones and people with more physical works (less educated). In the present study, $48(85.7 \%)$ of 56 patients were farmers and manual labors. The risk of developing kidney stones in people working outdoors or exposed to high temperatures is twice compared to people working at room temperature [39-41]. Hussein et al., [17] also reported that kidney stone patients are more likely to be physical workers with lower education level in Thailand and Malaysia. The reason for the high incidence of kidney stones in outdoor workers is that hot temperature might lead to dehydration, and people in these conditions have less access to drinking water. Excessive exposure to sunlight results in more production of vitamin $\mathrm{D}$ and this after conversion to 1,25-dihydroxy-vitamin $\mathrm{D}$ in kidneys, can promote calcium absorption in the gut [42].

According to Kuppuswamy [43] socio economic status classification, we have categorized our patients into 5 different groups. In the present study, 26 $(46.4 \%)$ of 56 patients with renal calculi belonged to lower middle class. Our results are in line with a recent report from India [37]. However, reports from other countries are quite different from our result [44, 45].

In this study, $38(67.9 \%)$ of 56 patients with renal calculi were non-vegetarians. Excessive consumption of meat protein might increase the risk of developing kidney stones because meat causes the over acidification of urine. Acidic urine causes the increased excretion of oxalate, calcium and uric acid, and decreases the excretion of citrate - which provides protection against stone formation. Dietary oxalate contributes to about half of the urinary oxalate [46].

This study shows that $47(83.9 \%)$ of 56 patients with renal calculi were consuming bore/tank 
water. This result is similar to the findings of a study from Italy [47]. They havefound that the extra meal intake of hard water enhances the risk for stone recurrence in patients since, being associated with an increased excretion of calcium and constant urinary levels of oxalate; it induces a relative super saturation of the calcium-oxalate product. They also reported that hard water enhances the risk for renal stones by the marked increase of the calcium-citrate index. However, a recent study from India, reported the high incidence of kidney stones in people consuming tap water compared to bore well water [37].

Results of this study suggest a significant association between all the epidemiological risk factors viz., gender, residence, occupation, socio economic status, diet, and source of water and formation of renal calculi (Table-4).

Most of the calculi were mixed variety (78.6\%) and commonest components noted were calcium oxalate in $38(67.9 \%)$, calcium phosphate in 34 $(60.7 \%)$, magnesium ammonium phosphate (struvite) in $12(21.4 \%)$, and uric acid in $12(21.4 \%)$. Ogaili et al., [48] reported that calcium oxalate $(64.6 \%)$ was the most common chemical composition in their study, followed by uric acid $(6.3 \%)$ and calcium phosphate $(0.6 \%)$. Even in a study conducted in Pakistan, it was seen that calcium oxalate was the most common composition (87.5\%), while uric acid, calcium phosphate, cystine and struvite were predominant compositions in $6.5 \%$, $1.29 \%, 0 \%$ and $4.3 \%$ respectively [49]. Khan et al., [50] reported that calcium oxalate the most common stone component in $78 \%$, uric acid in $19 \%$ and struvite in $3 \%$. Chemical analysis by Janakiram et al., [51] revealed that among 125 stones, the incidence of calcium oxalate stones was $36.8 \%$, calcium phosphate $24 \%$, mixed $19.2 \%$, struvite 12\%, Magnesium phosphate $6.4 \%$ and uricacid phosphate $1.6 \%$. Alatab et al., [52] reported that the calcium oxalate $(90 \%$ vs. $75 \%)$ and uric acid calculi (15\% vs. 5\%) are more common in developed countries than in developing countries, while the reverse is true for struvite stones (7\% vs14\%). Even in this study, struvite is present in 12 $(21.4 \%)$ of 56 stones.

The present study indicated that $53.6 \%$ of patients with renal calculi were complaining from UTI and this result is in consistent with other studies [30, 53, 54]. In this study, $26(86.7 \%)$ of 30 isolates were positive for urease enzyme. Previous studies suggested that there is a significant association between UTI caused by urease-producing organisms and stone formation [55-58]. Infection is frequently a coexistent lithogenic factor. Residual urine from outlet obstruction predisposes to infection, and combination of these factors may result in stone formation. Benway and Bhayani [59] reported that between 22-34\% of bladder calculi are associated with UTI and most commonly with Proteus organisms. In our study also $53.6 \%$ of stones are associated with UTI and Proteus was isolated from $10(17.9 \%)$ urine samples. Urease is necessary to split urea to ammonia and $\mathrm{CO} 2$, making urine more alkaline which elevates $\mathrm{pH}$ (typically > 7). Phosphate is less soluble at alkaline versus acidic $\mathrm{pH}$, so phosphate precipitates on to the insoluble ammonium products to for struvite stones. Until recently, only struvite stones were considered to be derived from bacterial infection. However, other types of stones such as calcium - based stones might also become secondarily infected with urease-splitting organisms and result in secondary struvite stone formation. These stones may contain a mixture of struvite and other materials [24, 25]. In this study, struvite is present in $21.4 \%$ of the stones. Results suggest that there is a significant association between UTI and renal calculi formation (Table-4).

\section{CONCLUSION}

This study has identified the epidemiological risk factors for formation of renal calculi and their composition among the ethnic population of Khammam district, Telangana, India. This study also attempted to determine the association between stone formation and UTI. We feel that small sample size is the limitation of this study and further studies with larger samples may be needed to determinethe association between stone formation and UTI.

\section{Compliance with Ethical Standards}

Funding: The authors received no specific funding for this work.

Conflict of interest: The authors declare that they have no conflict of interest.

\section{REFERENCES}

1. Mandel, N. (1996). Mechanism of stone formation. Seminars in Nephrology, 16,364-374.

2. Parmar, M. S. (2004). Kidney stones. BMJ, 328, 1420-1424.

3. Coe, F. L., Evan, A., \& Worcester, E. (2005). Kidney stone disease. Journal of Clinical Investigation, 115, 2598-2608.

4. Barbasa, C., Garciaa, A., Saavedraa, L., \& Muros, M. (2002). Urinary analysis of nephrolithiasis markers. Journal of ChromatographyB, 781, 433455 .

5. Giannossi, L., \& Summa, V. (2012). Areview of pathological biomineralanalysis techniques and classification schemes. AnIntroduction to the Study of Mineralogy, C. Aydinalp, Ed., In Tech Open, In Tech, IMAA-CNR, Italy, http://www.intechopen.com/books/.

6. Kumar, S. B. N., Kumar, K. G., Srinivasa, V., \& Bilal, S. (2012). Areview on urolithiasis, International Journal of Universal Pharmacy and Life Sciences, 2, 269-280. 
7. Ngo, T. C., \& Assimos, D. G. (2007). Uric acid nephrolithiasis: recent progress and future directions. Reviews in Urology, 9, 17-27.

8. Moe, O. W. (2006). Kidney stones: Pathophysiology and medical management. Lancet, 367, 333-344.

9. Ramello, A., Vitale, C., \& Marangella, M. (2000). Epidemiology of nephrolithiasis. Journal of Nephrology, 13, 45-50.

10. Robertson, W. G., \& Hughes, H. (1994). Epidemiology of Urinary Stone Disease in Saudi Arabia. In: Urolithiasis, Ryall, R., Bais, V., Marshall, A., Rofe, L., \& Smith, V. W. (Eds.). Plenum Press, New York, ISBN: 978-1-46136091-9,453-455.

11. Hussain, M., Lal, M., Ali, B., Ahmed, S., Zafar, N., Naqvi, S. A., \& Adib-ul-Hassan, R. S. (1995). Management of urinary calculi associated with renal failure. JPMA. The Journal of the Pakistan Medical Association, 45(8), 205-208.

12. Mitra, P., Pal, D. K., \& Das, M. (2018). Does quality of drinking water matter in kidney stone disease: A study in West Bengal, India? Investigative and Clinical Urology, 59, 158-165.

13. Urology and Andrology Centre. (2016). Kidney stones.

Services. http://www.dilipraja.com/stone.htm.

14. Ansari, M. S., Gupta, N. P., Hemal, A. K., Dogra, P. N., Seth, A., Aron, M., \& Singh, T. P. (2005). Spectrum of stone composition: structural analysis of 1050 upper urinary tract calculi from northern India. International journal of urology, 12(1), 1216.

15. Huang, W. Y., Chen, Y. F., Carter, S., Chang, H. C., Lan, C. F., \& Huang, K. H. (2013). Epidemiology of upper urinary tract stone disease in a Taiwanese population: a nationwide, population based study. The Journal of urology, 189(6), 2158-2163.

16. Pugliese, J. M., \& Baker, K. C. (2009). Epidemiology of nephrolithiasis inpersonnel returning from operation Iraqi freedom. Urology, 74, 56-60.

17. Hussein, N. S., Sadiq, S. M., Kamaliah, M. D., Norakmal, A. W., \& Gohar, M. N. (2013). Twenty-four-hour urine constituents in stone formers: a study from the northeast part of Peninsular Malaysia. Saudi Journal of Kidney Diseases and Transplantation, 24(3), 630-637.

18. Kale, S. S., Ghole, V. S., Pawar, N. J., \& Jagtap, D. V. (2014). Inter-annual variability of urolithiasis epidemic from semi-arid part of DeccanVolcanic Province, India: climatic and hydrogeochemical perspectives. International Journal of Environmental Health Research, 24, 278-289.

19. Kleiner, S. M. (1999). Water: an essential but overlooked nutrient. Journal of American Dietetic Association, 99, 200-206.
20. Pearle, M. S., Goldfarb, D. S., Assimos, D. G., Curhan, G., Denu-Ciocca, C. J., Matlaga, B. R., ... \& White, J. R. (2014). Medical management of kidney stones: AUA guideline. The Journal of urology, 192(2), 316-324.

21. Biradar, A. N., Patil, S. B., Yadawe, M. S., \& Kundargi, V. S. (2014). Influence ofwater quality on urolithiasis. World Journal of Pharmaceutical Research, 3, 483-487.

22. Devuyst, O., \& Pirson, Y. (2007). Genetics of hypercalciuric stone formingdiseases. Kidney International, 72, 1065-1072.

23. Andrew, L. S., \& Alan, J. W. (2017). The association between bacteria and urinary stones. Annals of Translational Medicine, 5, 32.

24. Kramer, G., Klingler, H. C., \& Steiner, G. E. (2000). Role of bacteria in the development of kidney stones. Current Opinion in Urology, 10, 35-38.

25. Rodman, J. S. (1999). Struvite stones. Nephron, 81 Suppl 1,50-59.

26. Mikawlrawng, K., Kumar, S., \& Vandana, R. (2014). Currentscenario of urolithiasis and the use of medicinal plants asantiurolithiatic agents in Manipur (North East India): a review. International Journal of Herbal Medicine, 2, 1-12.

27. Harold, V. (2005). Practical Clinical Biochemistry. Fourth edition. CBS Publisher and distributors: Delhi. Chapter 28, Stones; 717-723.

28. Golechha, S., \& Solanki, A. (2001). Bacteriology and chemical composition of renal calculi accompanying urinary tract infection. Indian $\mathbf{J}$ Urol. 17: 111-17.

29. Bianca, T., Adrian, M., Emil, M., \& Adrian, T. (2013). Microbiological study of Urinary Calculi in patients with urinary Infections. Acta Medica Transilvanica, 2, 245-249.

30. Bihl, G., \& Meyers, A. (2001). Recurrent renal stone disease--advances in Pathogenesis and clinical management. Lancet, 358, 651-656.

31. Silva, G. R., \& Maciel, L. C. (2016). Epidemiology of urolithiasis consultations in the paraiba valley. The Journal of the Brazilian College of Surgeons, 43, 410-415.

32. Welshman, S. G., \& McGeown, M. G. (1975). The relattionship of the urinary cations, calcium, magnesium, sodium and potassium, in patients with renal calculi. British Journal of Urology, 47, 237-242.

33. Nicar, M. J., Hill, K., \& Pak, C. Y. (1987). Inhibition by citrate of spontaneous precipitation of calcium oxalate in vitro. Journal of bone and mineral research, 2, 215-220.

34. Stamatelou, K. K., Francis, M. E., Jones, C. A., Nyberg Jr, L. M., \& Curhan, G. C. (2003). Time trends in reported prevalence of kidney stones in the United States: 1976-1994. Kidney international, 63(5), 1817-1823.

35. Wang, W., Fan, J., Huang, G., Li, J., Zhu, X., Tian, Y., \& Su, L. (2017). Prevalence of kidney 
stones in mainland China: A systematic review. Scientific reports, 7(1), 1-9.

36. Sas, D. J., Hulsey, T. C., Shatat, I. F., \& Orak, J. K. (2010). Increasing incidence of kidney stones in children evaluated in the emergency department. Journal of Pediatrics, 157, 132-137. https://doi. org/10.1016/j.jpeds.2010.02.004.

37. Prakash, R. (2019). Prevalence and sociodemographic status on kidney stone patients in Thanjavur district, Tamil Nadu, India. International Journal of Community Medicine and Public Health, 6(5), 1943-1947.

38. Basiri, A., Shakhssalim, N., Khoshdel, A. R., Ghahestani, S. M., \& Basiri, H. (2010). The demographic profile of urolithiasis in Iran: a nationwide epidemiologic study. International urology and nephrology, 42(1), 119-126.

39. Ganesamoni, R., \& Singh, S. K. (2012). Epidemiology of stone disease in northern India. In: Talati, J., Tiselius, H. G., Albala, D. M., YE, Z., editors. Urolithiasis: basic science and clinical practice, vol 1: epidemiology. London: Springer; 39-46.

40. Yoshida, O., \& Okada, Y. (1990). Epidemiology of urolithiasis in Japan: a chronological and geographical study. Urologia Internationalis, 45,104-111, https://doi.org/10.1159/000281680.

41. Tanthanuch, M., Apiwatgaroon, A., \& Pripatnanont, C. (2005). Urinary tract calculi in southern Thailand. Journal of the Medical Association of Thailand, 88, 80-85.

42. Freeg, M. A., Sreedharan, J., \& Muttappallymyalil, J. (2012). A retrospective study of the seasonal pattern of urolithiasis. Saudi Journal of Kidney Diseases and Transplantation, 23, 1232-1237.

43. Kuppuswamy, B. (1981). Manual of socioeconomic status (urban), Manasayan, Delhi.

44. Yasui, T., Iguchi, M., Suzuki, S., \& Kohri, K. (2008). Prevalence and epidemiological characteristics of urolithiasis in Japan: national trends between 1965 and 2005. Urology, 71, 209213.

45. Tae, B. S., Balpukov, U., Cho, S. Y., \& Jeong, C. W. (2018). Eleven-year cumulative incidence and estimated lifetime prevalence of urolithiasis in Korea: a national health insurance service-national sample cohort based study. Journal of Korean Medical Science, 33, e13. https://doi.org/10.3346/jkms.2018.33.e13.

46. Collele, J., Kochis, E., Galli, B., \& Munver, R. (2005). Urolithiasis/ Nephrolithiasis: What's it all about? Urologic Nursing, 25, 427-448.
47. Bellizzi, V., De Nicola, L., \& Minutolo, R. (1999). Effects of water hardness on urinary risk factors for kidney stones in patients with idiopathic nephrolithiasis. Nephron, 81 (Suppl 1), 66-70.

48. Ogaili, M., Nasser, M., \& Shrafadin, R. (2014). Chemical Composition of Urinary Stones in Patients with Urolithiasis in Sana'a, Yemen. British Biomedical Bulletin, 2, 412-417.

49. Bangash, K., Shigri, F., Jamal, A., \& Anwar, K. (2011). Spectrum of Renal Stones Composition; Chemical Analysis of Renal Stones. International Journal of Pathology, 9, 63-66.

50. Khan, A. S., Rai, M. E., Pervaiz, A., Shah, A. H., Hussain, A. A., \& Siddiq, M. (2004). Epidemiological risk factors and composition of urinary stones in Riyadh Saudi Arabia. Journal of Ayub Medical College Abbottabad, 16(3):56-58.

51. Janakiram, B., Sunitha, T., \& Babu, M. R. (2014). Etiology of urolithiasis from south indian population: correlation of recurrence and antibiotic resistance to biofilm production capabilities of uropathogenic microbes. International Journal of Pharma and Bio Sciences, 5, 909-919.

52. Alatab, S., Pourmand, G., \& El Howairis, M. E. F. (2016). National profiles of urinary calculi: a comparison between developing and developed worlds. Iranian Journal of Kidney Diseases, 10, 51-61.

53. Costa Bauza, A., \& Isern, B. P. (2005). Factors affecting the regrowth of renal stones in vitro: A contribution to the understanding of renal stone development. Scandinavian Journal of Urology and Nephrology, 39, 194.

54. Sayer, J. A. (2010). Renal disease. Nephron Physiology, 118, 35-44.

55. Thomas, B., \& Tolley, D. (2008). Concurrent urinary tract infection and stone disease: pathogenesis, diagnosis and management. Nature Clinical Practice Urology, 5, 668-675.

56. Bichler, K. H., Eipper, E., Naber, K. (2002). Urinary infection stones. International Journal of Antimicrobial Agents, 19, 488-498.

57. Miano, R., Germani, S., \& Vespasiani, G. (2007). Stones and urinary tract infections. Urologia Internationalis, (79 Suppl 1), 32-36.

58. Rieu, P. (2005). Infective lithiasis. Annalesd' Urologie, 39, 16-29.

59. Benway, M. B., \& Bhayani, B. S. (2012). Lower urinary tract calculi. In: Alan JW (ed.) CampbellWalsh Urology.10th ed. Philadelphia, USA: Elsevier; 2521-2527. 